\title{
Rituales, representaciones y rebeldías Análisis de la interrelación entre usuarios y espacio público en Barcelona*
}

\author{
Rituals, Representations and Rebelliousnesses \\ Analysis of the Interrelation between Users \\ and Public Spaces in Barcelona
}

\author{
RAÚL GARCÍA FERRER**
}

\begin{abstract}
A search is made for interrelations among spaces built as urban and its inhabitants. The method to produce information is participant observation performed throughout three ethnographicjourneys across the city of Barcelona's public space. Applying Lefebvre's theory of spatial triad and the theatrical metaphor inspired by Goffman it is shown how users of public space perform a practice of space with ritual links and, at the same time, are capable of creative improvisation which can belie the space conceived by the agents that project the city.
\end{abstract}

Key words: anthropology of space, ethnographic itinerary, spatial trialectics, theatrical metaphor

\begin{abstract}
Resumen
Se buscan algunas interrelaciones entre el espacio construido urbano y sus habitantes. El método para producir información es la observación participante realizada en tres recorridos etnográficos por el espacio público de la ciudad de Barcelona. Aplicando la teoría de los tres momentos del espacio de Lefebvre y la metáfora teatral inspirada por Goffman se muestra cómo los usuarios del espacio público llevan a cabo una práctica del espacio de tintes rituales $y$, asimismo, son capaces de una improvisación creativa que puede contradecir el espacio concebido por los agentes que proyectan la ciudad.
\end{abstract}

Palabras clave: antropología del espacio, itinerario etnográfico, trialéctica espacial, metáfora dramatúrgica

\section{Introducción}

L a ciudad constituye el paisaje arquitectónico y urbanístico erigido por la sociedad para resolver necesidades esenciales de su existencia y, a su vez, establece con sus moradores un flujo recíproco de materializaciones, significados, símbolos y estímulos que afecta radicalmente sus vidas cotidianas. Como hace el antropólogo Lluís Duch, calificar la urbe como de "realidad antropológica por excelencia" (2000: 472) es una definición bastante ajustada para unos territorios donde hoy se ubica poco más de la mitad de la población humana. Este texto sintetiza mi investigación, en clave antropológica, sobre cómo se dan las interacciones entre el medio urbano construido y sus habitantes, mediante el caso de estudio del espacio público de la ciudad de Barcelona. En concreto, interesa observar e interpretar los usos de los urbanitas así como los significados que les transmiten los

\footnotetext{
* Artículo recibido el 05/01/18 y aceptado el 05/03/18.

** Institut Català d'Antropologia, Grup de Recerca en Antropologia i Arquitectura. Carrer Casp 43, baixos 1a 08010 Barcelona, España <raulgarciaferrer@yahoo.es>. ORCID: https://orcid.org/0000-0002-5531-2736.
} 
elementos urbanísticos. Se trata de investigar aquello que Mikel Dufrenne plantea en el prefacio de Poétique de la ville cuando afirma que "los hombres producen su ciudad como la ciudad produce sus hombres, sin que ninguno de los participantes pueda vanagloriarse de una iniciativa o de una prioridad" (Sansot, 2004: 12). Este trabajo ${ }^{1}$ puede sumarse al reciente interés de la antropología hispanohablante por la ciudad, el urbanismo, la arquitectura y el espacio público, en contraste con una tradición ya de varias décadas en el ámbito francófono cuyas referencias teóricas van a ser fundamentales aquí.

\section{Propuesta teórica y metodológica para etnografiar lo urbano}

Mi aproximación a la interrelación ciudadanosciudad parte del rechazo de una idea del espacio como la dualidad de, por una parte, continente y, por otra, contenido (Signorelli, 1999). Esta posición teórica se refiere al espacio en un sentido antropológico, o si se quiere sociológico, en la dirección que manifestaba Heidegger de que "el espacio no es nada contrapuesto al hombre [...] No hay hombres y además espacio" (1997: 213). Idea que se puede agregar a otras como las de Simmel (1988), Bachelard (2000) o Merleau-Ponty (2003) y que se resume en la noción de lugar practicado de De Certeau (2000: 129) y en el concepto de producto social de Lefebvre (1972: 46).

Esta perspectiva del espacio como resultado de una modelación social es la base para la teoría trialéctica de análisis del espacio de Henri Lefebvre que en el presente artículo se aplicará para el caso del espacio público barcelonés. ${ }^{2}$ La pertinencia de aplicar a la etnografía de las calles de Barcelona el patrón de la trialéctica lefebvriana se fundamenta en su valor reflexivo para superar la idea de un espacio abstracto y objetivo como el que sostiene en la actualidad la ideología urbanística dominante, que invisibiliza su condición de constructo (Lefebvre, 2013). Se trata de un modelo de análisis compuesto por tres momentos. El primero es el espacio percibido o práctica espacial, experiencia cotidiana de los sujetos en su entorno y momento espacial en que se descifra el espacio mismo para poder actuar en él; brevemente: el espacio material y las prácticas de los cuerpos en él. El segundo es el espacio concebido o representaciones del espacio, el espacio mental y abstracto preponderante en cada tipo de sociedad que defienden, entre otros, políticos y urbanistas, para imponer el canon oficial de lo que se entiende por espacio. El tercero es el espacio vivido o espacios de representación, el espacio concreto de los usuarios, lugar de expresión y de acción, subversivo y precario, que se encuentra en pugna con el espacio dominante concebido. ${ }^{3}$

El instrumento teórico de los tres momentos del espacio, que funciona como filtro analítico para penetrar en la relación entre el entorno construido de la urbe y la sociedad que lo habita, se va a vincular, en esta investigación del caso barcelonés, con una interpretación de estas categorías con base en la metáfora dramatúrgica desarrollada inicialmente por Erving Goffman (1981) y retomada más tarde por Isaac Joseph (1988 y 1999); sin ignorar que el propio Lefebvre recurre a esta idea cuando trata la arquitectura como "escena" (2013: 95). El aspecto dramatúrgico del espacio se articula con la trialéctica espacial lefebvriana a partir de la correspondencia del espacio percibido con la performance de los intérpretes que son los usuarios del espacio público, del espacio concebido con el decorado que supone la ciudad planificada y construida que oculta entre bambalinas una ideología dominante, y, por último, del espacio vivido con una acción de los actores urbanitas más cercana a la improvisación y que se aleja de la interpretación de un papel coherente con el decorado planificado. En suma, se trata de conducir las categorías del espacio tripartito lefebvriano hacia el esquema metafórico del teatro para subrayar su condición de construcción social y contradecir el esencialismo naturalista del espacio y su derivación hacia el determinismo social.

La estrategia metodológica que adopto para producir la información necesaria para este proyecto sobre la urbe y sus habitantes sigue la recomendación de Ulf Hannerz de poseer una "buena dosis de eclecticismo" (1986: 344) llevado a término mediante el recurso a fuentes primarias y secundarias. Las primarias están integradas por la observación participante y la entrevista -la primera de estas dos es la más sustancial-, y las secundarias, por documentación historiográfica y de prensa, textos legales y bibliografía antropológica y sociológica. La observación supone la táctica troncal de esta etnografía porque permite que "los hechos hablen

\footnotetext{
1 Materializado en la tesis doctoral "Urbanitas y urbanismos. Recorridos etnográficos para entender la interrelación entre entornos construidos y usuarios en el espacio público de Barcelona”, defendida en la Universitat Autònoma de Barcelona en febrero de 2015.

2 En otro artículo he presentado un ejemplo de este modo analítico aplicado también a la realidad urbana (García, 2012).

3 Cabe valorar el éxito de la tesis de la trialéctica lefebvriana del espacio al observar que ha sido recuperada por otros autores de entre los que destacan David Harvey (1998), Edward Soja (1996), Setha Low (1996) o Manuel Delgado (1999).
} 
por sí mismos" (Malinowski, 1986: 37) constatando las expresiones de la sociedad y evitando caer en las racionalizaciones que elaboran los sujetos observados cuando éstos se autoexaminan (Horta, 2010). En otros términos, se trata de "no sólo preguntar; sino sobre todo escuchar y observar" (Giglia, 2012: 72). Un privilegio para "lo que se hace" por encima de "lo que se dice", dando prioridad a la mirada sobre la palabra, sin que ello signifique prescindir en absoluto de lo narrativo.

Selecciono como locus de esta investigación el espacio público de la ciudad de Barcelona que, en palabras de Manuel Delgado, constituye el ámbito de lo urbano por antonomasia (2000: 46). Esta elección parte, por un lado, del hecho de que la calle es el entorno donde se da la copresencia de la sociedad en sus múltiples actividades $\mathrm{y}$, por otro, de la oportunidad de llevar a cabo una observación antropológica muy amplia y accesible, que resultaría mucho más complicada de alcanzar en otros espacios de la ciudad.

La observación en el espacio público barcelonés se realiza mediante el tránsito a pie a lo largo de varios circuitos predeterminados que denomino, indistintamente, recorridos o itinerarios etnográficos. Esta metodología recoge la dualidad itinerario/mapa propuesta por Michel de Certeau (2000) que diferenciaba entre el primero, que atiende al hacer y a la narración del espacio, y el segundo, que crea una descripción absoluta y geométrica. El itinerario que propongo se cuida de lo cualitativo, pues el mero hecho de salir a recorrer las calles supone lo que Pierre Sansot describe como un "encontrarse desguarecido" (2004: 208), una actitud primaria que dispone a descubrir los límites y secretos de la ciudad que uno habita. Como en el trabajo ya clásico de Jean-François Augoyard (1979), ser nómada junto a la sociedad nómada de las calles provoca en el investigador una in-corporación, o embodiment, que refuerza la condición participante. Los itinerarios etnográficos encuentran un paralelo en los paseos sociológicos efectuados en París por Michel Pinçon y Monique Pinçon-Charlot (2013).

Los itinerarios etnográficos consisten en delinear un camino para andar a pie por el espacio público urbano con el criterio de atender al máximo de diversidad morfológica urbanística a la vez que histórico-social. El resultado son tres recorridos, de aproximadamente 12 kilómetros cada uno, a lo largo de nueve de los diez distritos de Barcelona, y que comprenden un seguimiento cronológico de la formación histórica de la ciudad, pues parten del distrito central y llegan hasta tres puntos de la periferia municipal. ${ }^{4} \mathrm{~A}$ falta de al- canzar una representatividad en sentido cuantitativo, tal diversidad morfológica y social pretende conseguir una significatividad en el sentido cualitativo.

La observación durante los itinerarios etnográficos se divide entre la realizada "en marcha" y la llevada a cabo "en reposo", ya que la mera acción de escribir en el cuaderno de campo obliga a detenerse. Pero no solamente por esta causa, sino porque allá donde el lugar lo permite se hacen altos en el camino para efectuar observaciones tanto panorámicas como particulares de las prácticas sociales y sus entornos materiales. Las sesiones de observación duran de una a cuatro horas al día en que se combinan deambuleos y "estacionamientos" dictados por las condiciones del lugar que el etnógrafo negocia con su entorno para integrarse en él. Teniendo presente el filtro de los tres momentos del espacio se anotan las actividades de los usuarios de las calles y se describe la envolvente arquitectónica y la forma urbanística en que se halla, mientras que el número de entrevistas / conversaciones con usuarios se reparte según una segmentación en tramos de cada itinerario.

\section{Etnografía en el espacio público}

Presento ahora la información recabada por medio de la observación participante y las entrevistas verificadas en el espacio público delimitado por los itinerarios etnográficos, así como aquella obtenida de fuentes de documentación secundaria. El conjunto de datos está categorizado por los tres momentos lefebvrianos del espacio, concertándolo con la metáfora dramatúrgica en cada caso.
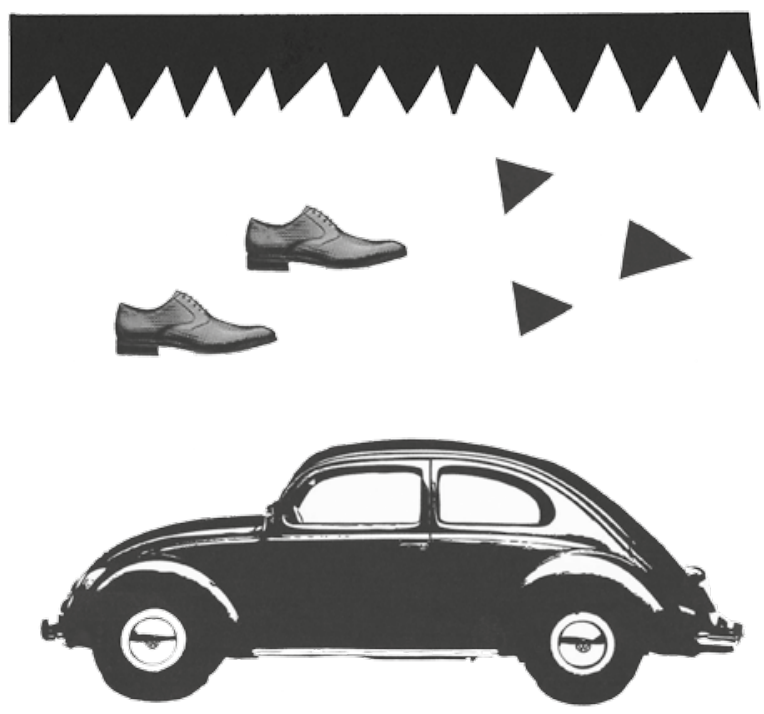

4 El trabajo de campo en los tres itinerarios se realizó durante 11 meses entre septiembre de 2012 y agosto de 2013. 


\section{Práctica espacial y actuación ritual}

El primero de los tres momentos, práctica espacial o espacio percibido, alude a cómo se produce la cohesión de la vida cotidiana en los diferentes entornos arquitectónicos y urbanísticos, que en esta investigación será el de los espacios públicos barceloneses visitados a través de los itinerarios etnográficos. Para constatar lo percibido se lleva a cabo, mediante la observación directa, una descripción de la composición arquitectónico-urbanística y de los usos habituales de los sujetos que pueblan esos espacios públicos. También se recogen las declaraciones de los usuarios de las calles entrevistados a lo largo de los tres itinerarios, así como la aportación de datos históricos sociourbanísticos sobre cada zona visitada.

El uso que comúnmente más se asocia con el espacio público es la circulación, transportarse uno mismo o transportar a otros o a objetos, ya sea a pie o mediante vehículos de distintas clases. Sin embargo, no deja de ser evidente que la calle se emplea para otros fines, por ejemplo, reunirse, descansar tomando asiento, estacionar vehículos o jugar y hacer deporte en zonas habilitadas para ello. El espacio público es lugar de interacción y de visibilidad donde las personas se exponen a la identificación y se ejercitan la reserva y el anonimato. A partir de estas propiedades, el momento de lo percibido se arma de un orden de interacción (Goffman, 1991: 169) que va a adaptarse a cada arquitectura y a cada tipo urbanístico de la ciudad construida.

El tránsito callejero se presenta de diversas maneras. En el distrito central de Barcelona, la Ciutat Vella, las calles tradicionalmente estrechas sufrieron durante el siglo xx operaciones de sventramento, aperturas de vías de mayor dimensión, como Drassanes, la Rambla del Raval o Via Laietana, donde, asimismo, se ha aprovechado para levantar grandes edificios en muchos casos para servicios públicos, oficinas y hoteles. Esto ha hecho que en tales espacios reconfigurados se priorice el uso para desplazarse ya sea a pie o en vehículos motorizados, de manera que, a pesar del espacio existente, en Drassanes y en Laietana no hay bancos para sentarse. En una parada de autobús en Drassanes, un anciano decepcionado ante una vía tan amplia que niega la opción de sentarse exclama: “Qué bonito sería que aquí pusieran unos bancos”. En sentido inverso, otras de estas reformas han favorecido la reunión, como ocurre en la Rambla del Raval, el Forat de la Vergonya o los jardines de Sant Pau del Camp. Ahí los bancos son puntos de reunión que muchas veces constituyen un recurso de inmigrantes indostaníes del barrio para encontrarse y conversar -se advierte por su aspecto, indumentaria e idioma-; mientras que Sant Pau es intensamente utilizado por quienes pasean a sus perros, pretexto para entablar relaciones entre vecinos. Uno de ellos opina sobre actividades que están fuera de lo que para él sería aceptable: "Yo llevo un año aquí, pero he visto cada cosa que...”. En este distrito hay un elevado porcentaje de calles de exclusividad peatonal, algunas de ellas con una alta densidad de comercios que provoca una masa humana en continuo movimiento, como ocurre en la calle de Portaferrissa, donde un joven que intenta atraer clientes a un establecimiento cercano define esta vía "como un sitio con muchísimo movimiento; un buen sitio donde captar (clientes)”. En ese sentido es la Rambla, corazón simbólico de la ciudad, un río de viandantes de entre los que destacan por su número aquellos que hacen turismo; visitantes que, obedeciendo las imágenes que vende la mercadotecnia turística internacional, se ven impelidos a peregrinar por esta avenida y también por el mercado de la Boqueria. En ambos espacios dominan negocios dirigidos al turista. La dueña de un restaurante -aunque reticente a mis preguntas- no puede evitar confirmar que "esto es una mina”, refiriéndose al éxito económico por estar situada en el núcleo turístico de la ciudad (véase foto 1 ).

Los recorridos etnográficos parten del centro histórico y se encuentran con el Eixample (ensanche), una zona urbanizada en cuadrícula con vías amplias donde la superficie de la calle se reparte equitativamente entre calzada y acera, que permite una mayor presencia de tráfico rodado que peatonal debido a la facilidad que se da al primero respecto a otros distritos de la ciudad. En el barrio del Eixample denominado Dreta de l'Eixample se aprecia un vaciamiento de peatones, aspecto sobre el cual el conserje de un edificio opina: "No hay vida de barrio, nunca lo ha sido [...] Los domingos esto está desierto”. En la zona contigua a la que conduce el itinerario, alrededor del Passeig de Sant Joan, la densidad edificada no ha dejado espacio a parques para el relajo; "no hay zonas verdes suficientes", denuncian dos mujeres que pasean a sus perros en la plaza de Tetuán.

Al contrario que en la Dreta de l'Eixample, en otras áreas observadas, más periféricas, es decir, más allá del centro y del distrito del Eixample, se aprecian usos que permiten afirmar una proximidad del espacio público con sus convecinos. "Es como un pueblecito [...] Está muy guapo este barrio”, declara un habitante del polígono de Montbau, o: "Para mí es un punto telúrico de Sarrià, lo encuentro súper acogedor”, comenta un joven que alaba una recoleta plaza de Sarrià. Estos ejemplos corresponden a dos urbanismos muy distintos: Sarrià es el de un municipio decimonónico de 


\section{Foto 1}

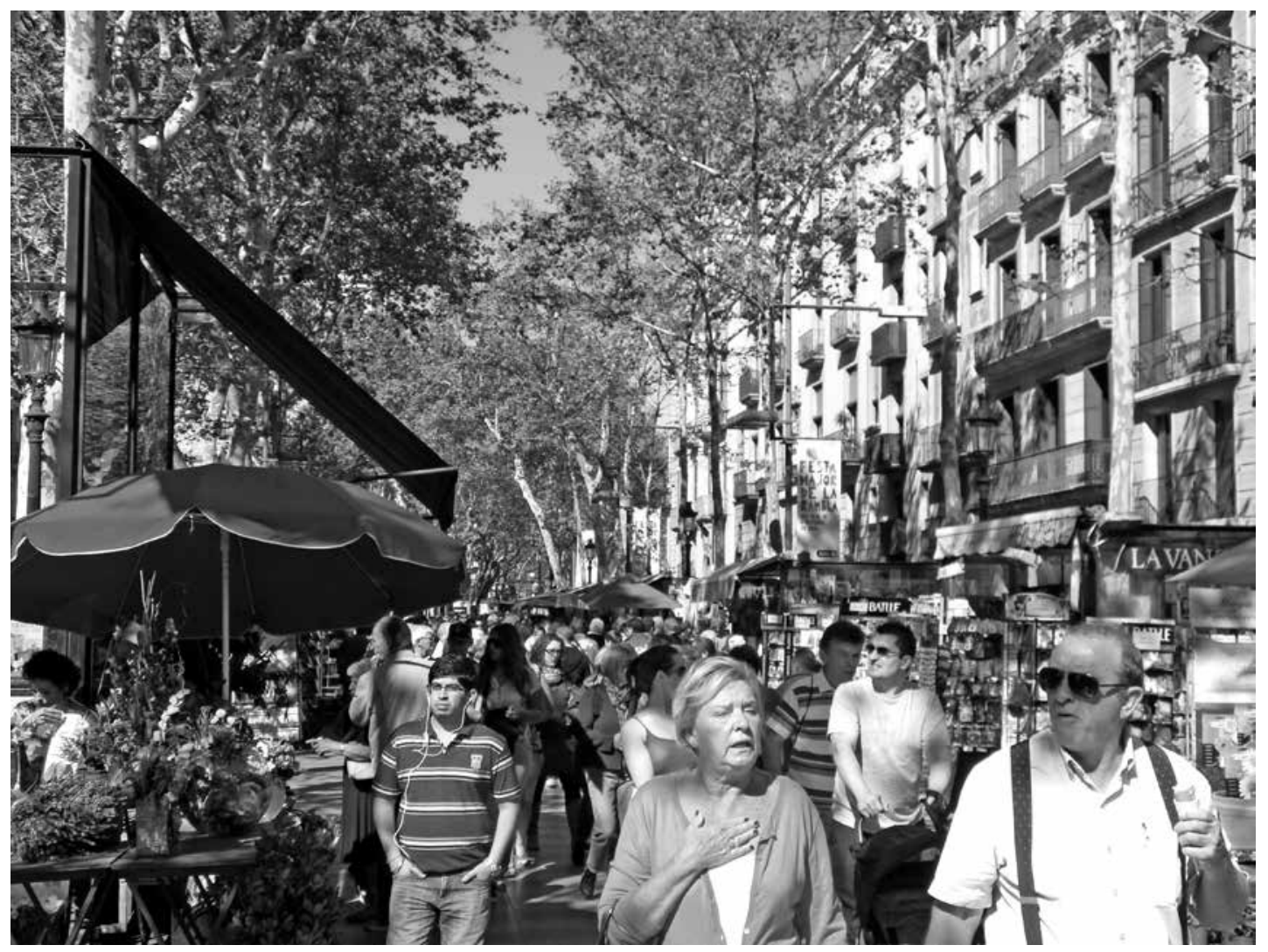

La intensa práctica del espacio de las Ramblas

espíritu rural con calles y plazas pequeñas y edificios de dos a cuatro plantas de altura, mientras que Montbau es el primer polígono barcelonés de estilo racionalista levantado al borde de la ciudad a mitad del siglo xx, compuesto por bloques habitacionales de media y gran altura. Materialidades edificadas muy diferenciadas, pero experiencias vecinales parecidas.

Por último, cabe mencionar la práctica de dos zonas urbanas donde destaca la ausencia de ocupación de las calles. Una es el barrio de Tres Torres, con sus pequeños bloques de viviendas de lujo con espaciosos y elegantes vestíbulos, que no dejan espacio para situar comercios, y que están equipados con ajardinamientos donde únicamente aparecen los conserjes/vigilantes que se asoman a contemplar la calle y afirman: "Una zona más que tranquila. No ves a nadie por las calles”. La otra es La Llacuna del Poblenou, cuyo pasado industrial hoy prácticamente desaparecido y sustituido por solares yermos y modernos edificios de empresas tecnológicas hace que sus escasos residentes sean casi una anomalía en el paisaje: "Paso porque es una zona de paso, pero no tiene nada de agradable", declara un joven vecino.

Esta cotidianidad de los urbanitas y la materialidad que la acoge es lo que Lefebvre ha caracterizado como práctica espacial. Los rasgos de este momento del espacio permiten una correspondencia descriptiva con la metáfora dramatúrgica en cuanto que los usuarios del espacio público interaccionan entre ellos y con su entorno construido como intérpretes de roles muy definidos, por ejemplo, la forma en que se camina por la vía pública evitándose y manteniendo posiciones y ritmos concretos, el modo de sentarse en bancos y cómo se comparten con sujetos desconocidos, etcétera. Una performance que alcanza la categoría de acción ritual, puesto que los "intérpretes" siguen un orden ceremonial específico en sus rutinas. Los actos cotidianos de las actividades en el espacio público se ritualizan al estar favorecidos por el pequeño número de opciones que esquematizan la ciudad concebida constituida por la planificación y programación urbanística. El espacio se descifra en su práctica diaria como un repertorio de "modelos reducidos" (Lefebvre, 2013: 161) que son coherentes con las conductas motivadas por el espacio planificado por urbanistas, arquitectos, políticos, etcétera.

La interacción, y concretamente la que se da en el espacio público como orden para la práctica espacial, resulta en lo que Honorio M. Velasco denomina difuminación del ritual, dado que "se ha acabado 
desustanciando el rito, que ha terminado por adquirir una forma adjetivada" (1996: 103). Su condición ritual, como mínimo en un sentido adjetivo, sirve para entender los ritos de interacción como modelo débil de sacralidad (Cruces, 2007: 69), expuesto por Goffman en Ritual de la interacción, y que Martine Segalen ha calificado de "rituales seculares" (2005: 124). Goffman concibe lo ritual más allá de la acepción clásica de la antropología vinculada con las ceremonias religiosas explícitas, conduciéndolo al terreno de las relaciones cara a cara, ampliando la definición de Radcliffe-Brown (1986: 142) $)^{5}$ como actividad que "representa una forma en que el individuo debe proteger y designar las consecuencias simbólicas de sus actos, mientras se encuentra en presencia inmediata de un objeto que tiene un valor especial para él" (Goffman, 1970: 56). Para Goffman, la persona es un objeto ritualmente delicado y la "cara de uno" -la que el autor estudia en la interacción llamada "cara a cara"- es "una cosa sagrada, y por lo tanto el orden expresivo necesario para sostenerla es de orden ritual" (1970: 25). El yo en la sociedad moderna se plantea como un objeto sagrado que tendrá que ser tratado ceremonialmente bajo cuidados rituales que conduzcan a un equilibrio que Goffman tilda de ritual (1970: 41). Joseph, recogiendo el trabajo goffmaniano, explicará las interacciones como intercambios en "que las personas se veneran recíprocamente, que participan en una especie de li-

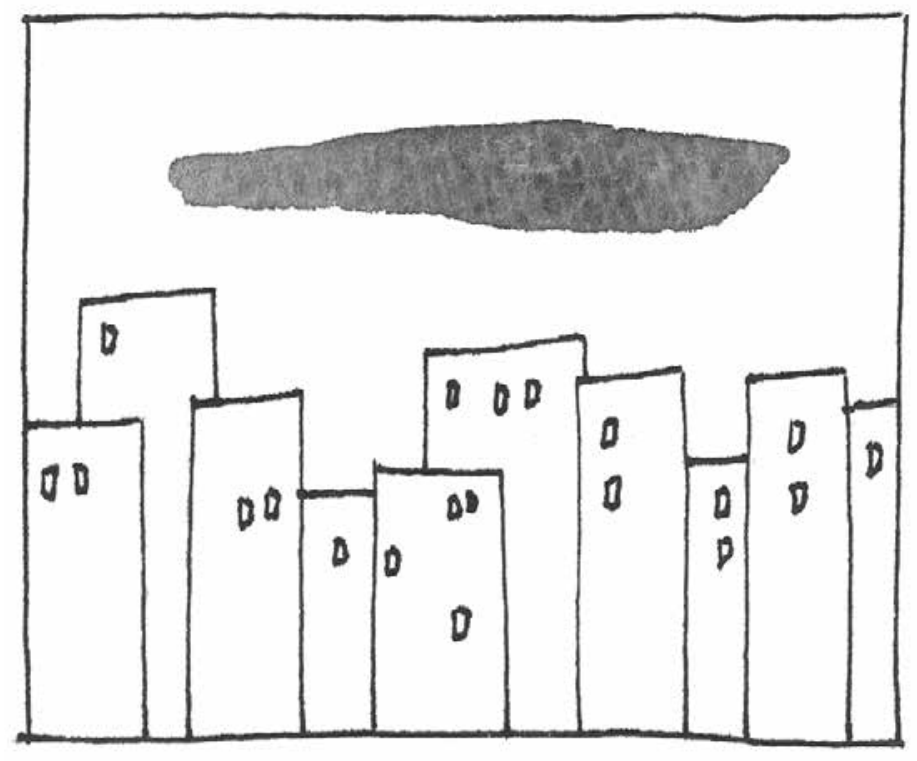

turgia cotidiana" (1988: 122), y llega a afirmar que el doble lenguaje dramatúrgico "es una cuestión de veneración del socius, es una forma mística del espacio público (unio mystica)" (1988: 129).

Así, las expresiones de la vida cotidiana observadas en las calles y plazas de Barcelona las entiendo como actividades ritualizadas que producen y reproducen un orden social en relación con las interacciones entre personas y entre personas y el espacio urbanizado material. La mayoría de los fenómenos se engloba en la movilidad, donde los espacios son transitados bajo un orden designado, por ejemplo, por las aceras, las calzadas, los pasos de cebra, las calles peatonales o los accesos a los edificios y sus antesalas, pero también se ritualizan los usos del mobiliario urbano y todas las actividades formales que los gestores de la ciudad permiten o promueven, como fiestas oficiales y eventos públicos de diversa índole.

\section{Espacio concebido y decorado escénico}

El segundo momento del espacio según Lefebvre -espacio concebido o representaciones del espacioes un ideal, una abstracción para crear un orden que se proyecta espacialmente. El espacio concebido es aquel que promueve el grupo dominante de cada sociedad y en cada época para perpetuarse legitimando un tipo específico de reproducción social. El poder dominante patrocina un saber que gestionarán urbanistas, técnicos, burócratas, fuerzas policiales, etcétera, que se materializará en planes urbanísticos, tipologías edificatorias, normativas ciudadanas y toda clase de estrategias para naturalizar el sistema de valores vigente. Alrededor del intérprete del espacio practicado, y siguiendo con la metáfora dramatúrgica, se levanta un decorado teatral que, al mismo tiempo, oculta entre bambalinas la cara opuesta. ${ }^{6} \mathrm{El}$ decorado de cara al público se correspondería, principalmente, con el entorno urbanístico y arquitectónico que conforma la envolvente de calles y plazas. Tras este "montaje escénico", la ideología dominante estructura ese orden urbano de acuerdo con los parámetros ideológicos que detentan los agentes ${ }^{7}$ que producen la ciudad concebida.

Los trayectos que dibujan los itinerarios etnográficos permiten, en su ruta desde el centro urbano hasta la periferia, observar la forma urbanística que

5 Goffman (1970: 56) reconoce haber ampliado la definición de Radcliffe-Brown en su término respeto para incluir otros tipos de éste.

6 La idea de escenario/bambalinas también proviene del desarrollo de la metáfora dramatúrgica descrita por Goffman (1970 y 1979).

7 Según el geógrafo Horacio Capel, los agentes son: los propietarios de los medios de producción, los propietarios del suelo, los promotores inmobiliarios, las empresas de la construcción y los organismos públicos (1983: 85). 
cada época histórica ha ido perfilando en el plano de Barcelona. En el distrito central, Ciutat Vella, se aglutina la complejidad de la acumulación de siglos de actividad urbanística: calles estrechas medievales donde los edificios han ido creciendo en altura por la carencia de suelo; aperturas y ensanchamientos viales planeados en el siglo xix y llevados a cabo en el xx arrasando con el pasado, como ocurre con Via Laietana, la avenida de Drassanes o Francesc Cambó; revisiones posmodernas como el entorno del Forat de la Vergonya y construcciones ex novo como el barrio reticular de la Barceloneta del siglo xviII son algunos ejemplos destacables. A continuación, el distrito histórico queda circundado por el Eixample, un nuevo urbanismo pensado para la moderna ciudad industrial del siglo XIX, un diseño racional, isotópico y destinado a una burguesía que quiere abandonar el antiguo régimen. Por último, el crecimiento final de la ciudad anexionándose pueblos cercanos como los visitados Sarrià, Gràcia o Les Corts, cuyos planos mezclan lo rural con lo urbano, y la formación de polígonos habitacionales periféricos como Montbau y La Verneda para alojar la fuerte inmigración recibida durante la década de los sesenta del siglo xx, todo ello "circunnavegado" por el cinturón viario de las Rondas, construidas para las olimpiadas de 1992.

El decorado urbano, constituido por el conjunto de la arquitectura expuesta a la vista del ciudadano en el espacio público, inscribe en la ciudad categorías sociales, por ejemplo, las diversas calidades de los edificios residenciales, los cuales suponen el mayor porcentaje del parque inmobiliario de la metrópoli. Aun así, destaca la concentración de esfuerzos simbólicos visibles en ciertas estéticas edilicias a partir de las tipologías constructivas ajenas al uso habitacional. George Balandier las llama "teatros" en los que la sociedad "oficial" se produce y mediante los cuales "se expresa el poder y se impone su sacralidad, mejor de lo que podría hacerlo cualquier explicación" (1994: 26). Históricamente han sido los templos cristianos, como en los itinerarios se ha mostrado con la Catedral, Sant Agustí, Betlem, Santa Maria del Mar o Sant Pere de les Puel-les, y la sedes del poder político, como el Gobierno Civil, la Llotja, el Palau de la Virreina y las actuales sedes de distritos de Sarrià, Gràcia o Sant Martí, los que se han servido de los lenguajes de los estilos arquitectónicos más grandilocuentes según el estilo de cada periodo para presentar sus valores a la vista de los ciudadanos. Hoy en día, nuevas tipologías reivindican esa sacralidad manifestada por Balandier, así ocurre con los rascacielos de oficinas observados en la avenida de las Drassanes, la zona 22@en Poblenou y la plaza dels Països Catalans; los hoteles en la Rambla del Raval, la Rambla o la plaza de Espanya; los equipamientos del arte y la cultura, como el museo de arte contemporáneo, L'Auditori, el Teatre Nacional de Catalunya y los centros cívicos de Bon Pastor y Poble Sec; o los edificios de los cuerpos de seguridad, como comisarías de mozos de escuadra (policía autonómica) y policía nacional. Siguiendo con la metáfora teatral, se puede comprobar cómo la mayoría de estos decorados se proveen de un "proscenio", es decir, de una antesala que garantice las perspectivas visuales adecuadas y marque jerárquicamente diferencias con el entorno. Estos proscenios son las plazas y los grandes espacios libres ante las fachadas de los edificios en cuestión.

La Barcelona contemporánea recurre sin disimulo a la espectacularización de la arquitectura para sus nuevas construcciones, reforzándola con el plus de publicidad y prestigio que da la autoría del proyecto por parte de arquitectos-estrella globales, entre otros, Richard Meier, Ricardo Bofill, Richard Rogers o Enric Miralles. A su vez, el patrimonio histórico urbanístico y arquitectónico, higienizado y reinterpretado en clave museística e identitaria desde hace ya un siglo (Ganau, 1997) y observado sobre todo en la "Barcelona romana y gótica" con dos de sus lienzos de murallas en la avenida de la Catedral y en la plaza de Ramon Berenguer el Gran, se ve completado con la incorporación de la arquitectura industrial del siglo xIx; esta última constituida por restos fabriles como fachadas o chimeneas en la calle de las Tàpies, en los jardines de Sant Pau del Camp, en La Llacuna del Poblenou, en el parque del Clot o en la calle de Melcior de Palau, que Delgado califica de "muestras exaltadas de arqueología industrial" y "refuerzo simbólico para una determinada ideología de identidad artificialmente favorecida desde instancias políticas" (2001: 16 y 10).

La ciudad-espectáculo (Fernández, 1990: 133) a base de impactos visuales también se materializa como representaciones del espacio altamente teatralizadas en los vanguardistas mercados municipales reformados, Santa Caterina y Barceloneta, y en los centros comerciales como Arenas, L'Illa Diagonal y Glòries, que conforman la última generación de hitos turísticocomerciales de la ciudad. Se cumplen las palabras del primer párrafo de La sociedad del espectáculo, de Guy Debord: "La vida entera de las sociedades en las que imperan las condiciones de producción modernas se anuncia como una inmensa acumulación de espectáculos. Todo lo directamente experimentado se ha convertido en una representación" (2009: 37). Nos encontramos ante operaciones constructivas típicas de la posmodernidad en que los diseñadores se alejan de los objetivos sociales promulgados por la 
modernidad, haciendo del espacio algo autónomo a lo cual dar forma bajo objetivos y principios estéticos alejados de tales preocupaciones (Harvey, 1998: 85).

No sólo la arquitectura más grandilocuente sino el mismo espacio público ofrece una fuerte sobredeterminación de usos que fomenta la ya comentada ritualización del espacio practicado. En las zonas programadas para la movilidad que favorecen el turismo y el comercio los bancos para sentarse son inexistentes, mientras que en los barrios periféricos se crean grandes parques (Clot, Sant Martí, Vall d'Hebron) con la intención de compensar las deficiencias habitacionales de los apáticos bloques dormitorio. Para evitar quiebres de los protocolos previstos por el poder municipal, se extienden por la ciudad dispositivos para el control de los cuerpos como rejas, vallas, mecanismos antiasiento, cámaras de vigilancia y zonas con intensa presencia policial (véase foto 2 ).

Tras todo el decorado que he descrito, las bambalinas ocultan la ciudad concebida inmaterial formada por el soporte legal-normativo que fiscaliza la calle con el propósito de blindar sus usos de cara a construir la imagen de marca de la ciudad desconflictivizada y educada hasta límites ridículos. Así ocurre con los discursos de la Ordenanza Cívica y de la Ordenanza de los usos del paisaje urbano de la ciudad de Barcelona, los cuales intentan normativizar toda actividad imaginable dejando fuera de juego el sentido común con que tradicionalmente se ha guiado todo peatón a la hora de practicar la ciudad. Su objetivo es una higienización social, que ya era la base de las grandes transformaciones urbanas del siglo xIX que dirigieron la mutación de la ciudad medieval amurallada hacia el crecimiento metropolitano de la era industrial. Hoy los términos se hacen más sutiles, pero se mantiene el espíritu de la analogía médica: se habla de espacios enfermos, regeneración, metástasis positiva, sutura urbana... "artificios todos ellos que permiten a los arquitectos, urbanistas y planificadores presentarse como "médicos del espacio" y que, más importante aún, "promueve que la ciudad moderna no deriva de la sociedad capitalista sino de una enfermedad de la sociedad" (Lefebvre, 2013: 154). La desaparición material de urbanismos para la clase obrera, considerados ahora desfasados, como las casas baratas del Bon Pastor o las de la Colònia Castells, es muestra de la imposibilidad de que existan modelos urbanísticos ajenos a la ciudad del capital neoliberal y que, con objeto de deslegitimizarlos, son presentados como antihigiénicos.

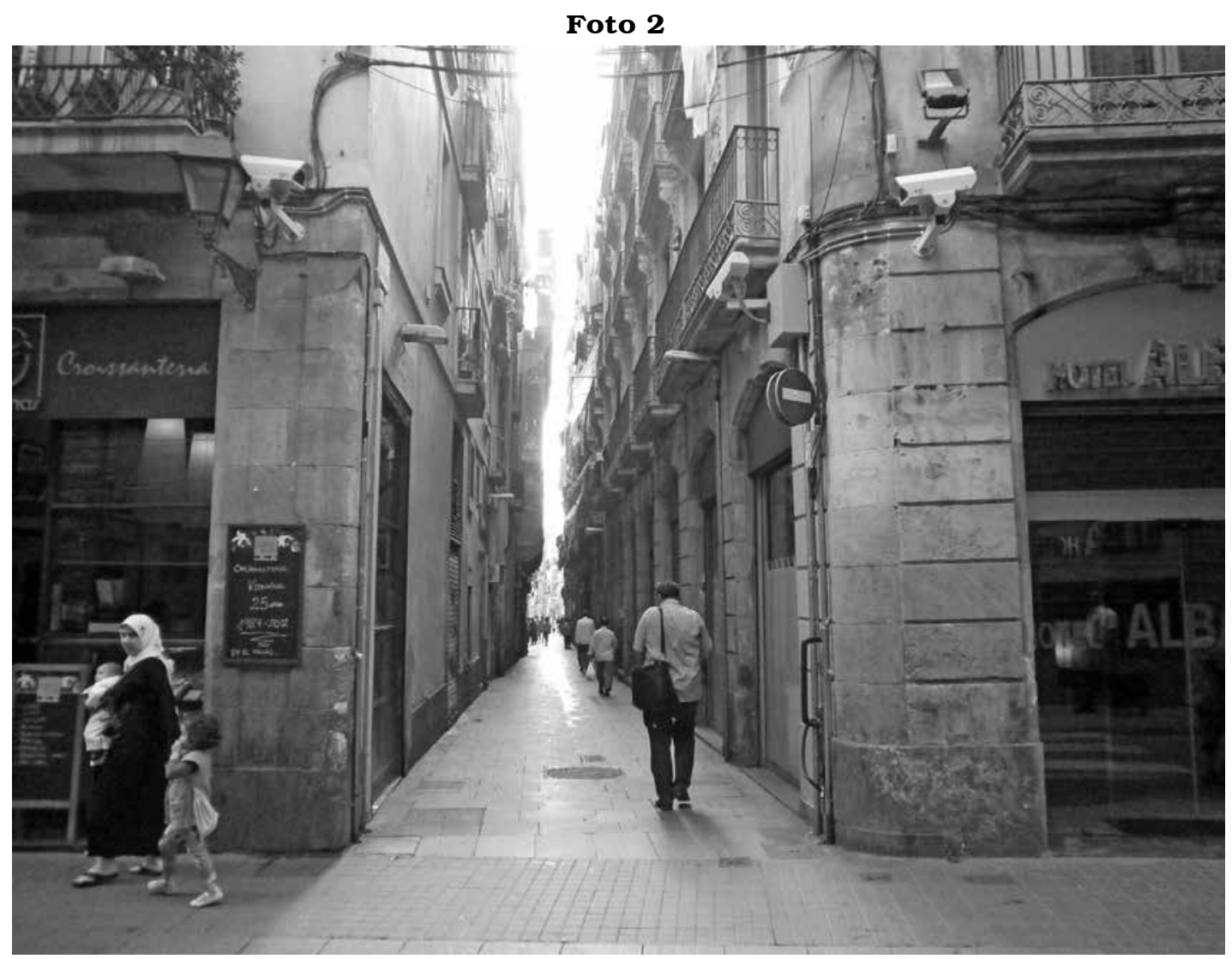

Cámaras de vigilancia en el espacio público del barrio antiguo 


\section{Espacio vivido e improvisaciones rebeldes}

El tercer momento del espacio -espacio vivido o los espacios de representación- es el lugar de los conflictos, de reunión y "lugar de deseo, lugar donde el deseo destaca por encima de las necesidades" (Lefebvre, 2013: 181). Es decir, el espacio cualitativo de lo vivido por los urbanitas, que se contrapone al espacio abstracto y frío del orden geométrico del espacio concebido.

La articulación de lo vivido con la metáfora teatral parte desde un principio del mismo término que utiliza Lefebvre al designarlo como espacio de "representación”, dando a entender su condición performativa. Una dramatización que, a diferencia de la interpretación ritualizada asociada con el primer momento del espacio ya comentado, libera de "la tiranía del signo y de las imposiciones imaginarias del márquetin urbano" (Joseph, 1999: 52), esto es, del espacio concebido. Para Joseph consiste en instituir el espacio en intriga y describirlo como espacio de acción, de socialización, de un actor que "es mucho más que un intérprete" (1988: 30), calificable de “actor de improvisación”, dado que hace de la calle un escenario de intrigas debido a la liquidez y la libertad que resulta de un, nunca completado, "trabajo de la sociedad sobre sí misma” (Delgado, 1999: 140) que conspira contra el espacio concebido.

La observación atenta a lo largo de los itinerarios etnográficos advierte una gran diversidad de tipos de espacio vivido donde se ejemplifica la idea de "apropiación” del espacio tal como la plantease Lefebvre (2013: 213) en oposición a la idea de "propiedad" relacionada con el espacio dominante. Uno de los actos del espacio vivido más visibles de los usuarios del espacio público se vincula con el descanso. Contrario a la lógica de la calle pensada principalmente para desplazarse, las personas resignifican lugares usándolos para sentarse, reunirse, dormir o comer. El césped de la centralísima plaza de Catalunya es un punto muy utilizado para sentarse a comer, dormir la siesta o simplemente aposentarse y conversar entre amigos. De manera más insólita, si cabe, una pareja con su bebé hacen un pícnic sobre el duro suelo de la Rambla del Raval, mientras que otros sujetos transforman obras de arte público en asientos para platicar o leer el diario, como se observa en las gigantescas letras-escultura que forman la palabra Bàrcino junto a la Catedral o en la gran escultura titulada Porta de Sarrià en el barrio del mismo nombre. Reuniones más concurridas se dan, por ejemplo, cuando se organizan fiestas de cumpleaños infantiles que incluyen comida, decoración y organización de juegos ocupando rincones de algunos jardines o parques, como se ha constatado en el parque de Joan Miró o en los jardines de las Infantes y Doctor Robert. Estas fiestas han provocado cierta polémica y el ayuntamiento barcelonés ha llegado a tomar cartas legales en el asunto (véase foto 3).

Foto 3

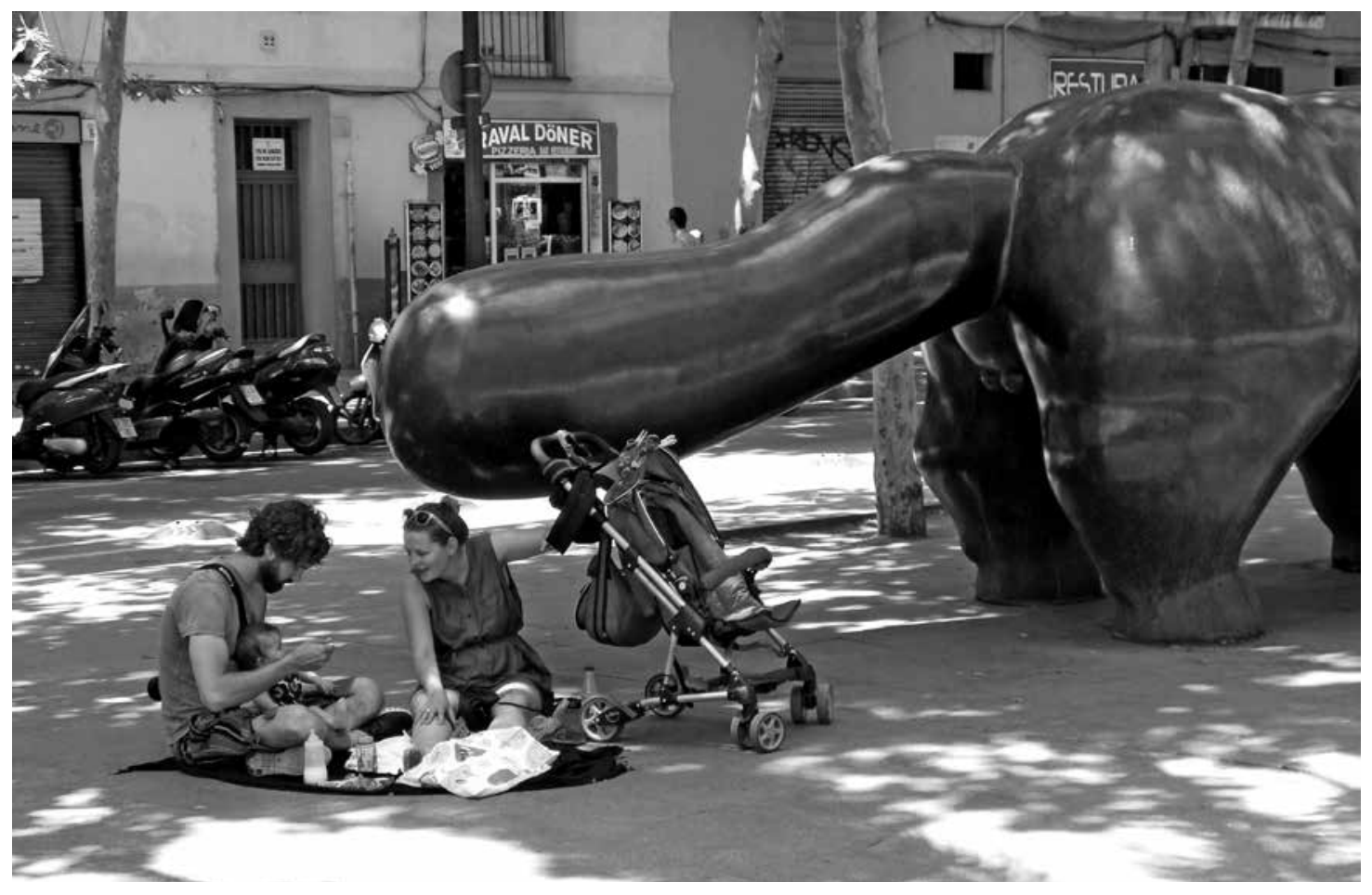

Uso alternativo de la calle en la Rambla del Raval 
Si, como expresaba más arriba, la comunicación y el desplazamiento son algunas de las prerrogativas del espacio concebido, lo vivido también crea sus propias movilidades. Es el caso de los bicicarros que aprovechan su tamaño y escasa velocidad para pasar tanto por aceras como por calzadas o por ambas a la vez, como ocurre en la calle del Hospital, donde uno de ellos es capaz de transitar en sentido contrario valiéndose de la habilidad de apoyarse al mismo tiempo en la parte peatonal y en el asfalto para no acabar de infringir las reglas por completo. O el uso indiscriminado por parte de los skaters de cualquier superficie: calzada, acera, carril bici, etcétera, para desplazarse por la ciudad. La creatividad se materializa literalmente cuando el urbanita es capaz de abrir senderos nuevos, alternativos a las vías planificadas ordinarias, al conformar desire lines ${ }^{8}$ como las observadas en un baldío de Via Trajana o acortando un camino en forma de $\mathrm{S}$ en la plaza de la Clota.

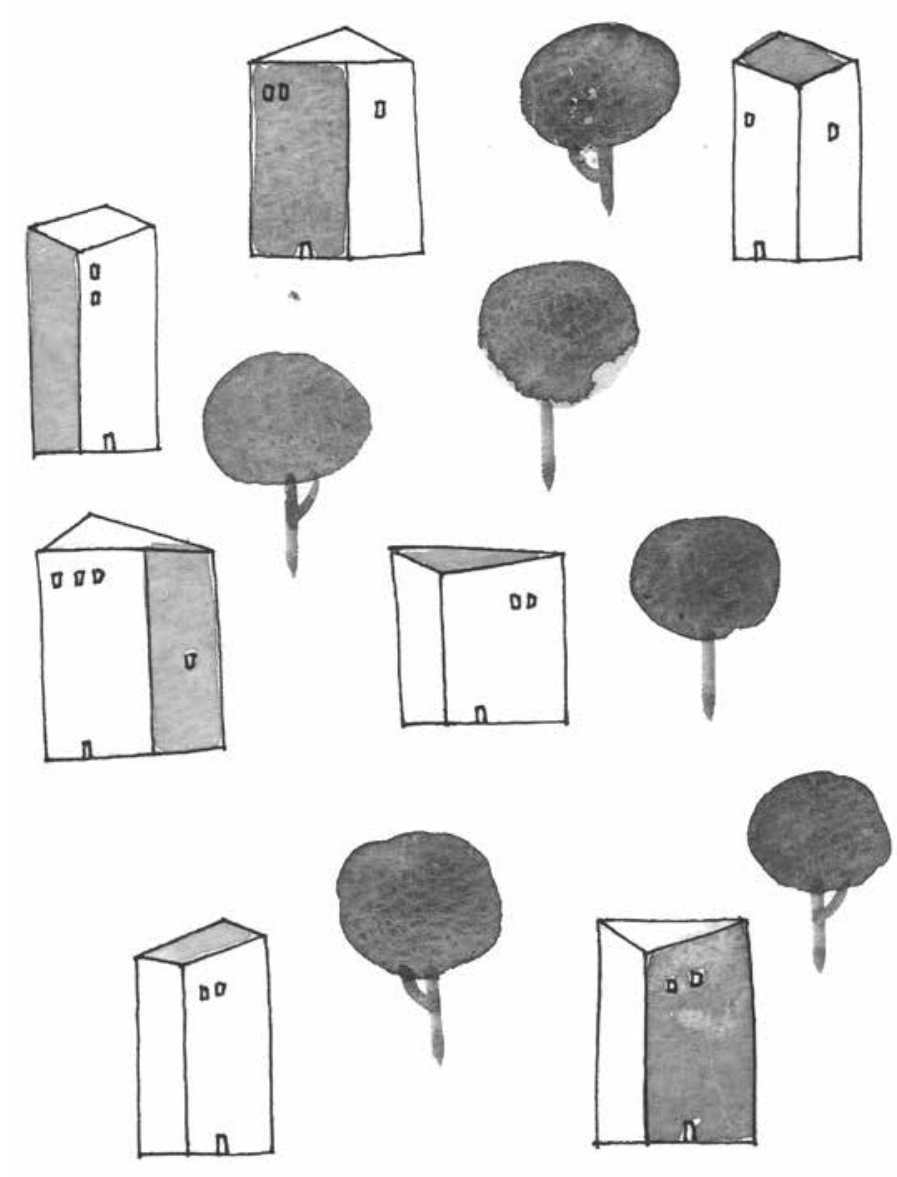

Esta materialidad es algo que también se advierte en la ingente presencia de obras de arte de carácter no oficial que se exponen en el espacio público, el llamado street art. La más abundante es la pintura mural o grafiti, que en algunos lugares compone un auténtico museo al aire libre, como ocurre en los muros perimetrales de un descampado en la calle de Ca n'Oliva en la periferia del municipio barcelonés. Además cabe destacar otros formatos de arte plástico en la vía pública: pósteres, carteles troquelados, baldosas cerámicas impresas de una sola pieza y formando mosaicos a base de, ya sea, diminutas teselas, latas de bebida o tapas de botella. Se ha observado que todos estos nuevos tipos se concentran mayoritariamente en el barrio del Raval y de Santa Caterina en el distrito histórico barcelonés.

Frente a la formalidad del espacio concebido y a la práctica cotidiana que éste desencadena se extiende una larga lista de actividades alternativas a las que la calle da cobijo. Me refiero tanto a lo laboral como a lo deportivo, ambos combatidos en diferentes grados por las ordenanzas municipales. La calle se convierte en escenario para ganarse la vida de manera informal, y casi siempre ilegal, cuando se pide limosna, se venden productos, se representan actuaciones artísticas, se recuperan desperdicios o se ofrecen servicios sexuales. Los tres primeros recurren a las oportunidades que brindan las zonas más masificadas y que incluyen una gran afluencia de turistas, por ejemplo en la plaza de Catalunya, el Passeig de Gràcia o las Ramblas. Los recuperadores de cartón, papel y metal recorren con sus carritos de supermercado toda la ciudad, habiéndolos observado tanto en el centro como en los distritos más periféricos como Sant Martí, Sant Andreu o Les Corts. Por otra parte, es en la estrecha y, al mismo tiempo, remodelada calle de Robador en el Raval donde persiste una fuerte presencia de mujeres que se ofrecen sexualmente y que son monitoreadas continuamente por la policía, constituyendo uno de los últimos reductos "a la vista" de esta actividad en Barcelona.

La realización de "deportes informales" como el skateboarding o el parkour se suma a la práctica "informal de deportes" cuando se trata de deportes formalizados ejercidos en entornos y condiciones alternativas. El skate y el parkour hacen de la propia materialidad urbana su razón de existir, por ello precisan de geometrías físicas adecuadas a sus movimientos: una larga pendiente peatonal en el Pas d'Isadora Duncan en el periférico Vall d'Hebron o los desniveles volumétricos

\footnotetext{
8 Las desire lines, o líneas de deseo, son los senderos que se van construyendo a través de las pisadas de los caminantes formando un camino alternativo (Muñoz-Alonso, 2012).
} 
que ofrecen las plazas dels Àngels y dels Països Catalans. Las informalidades deportivas aparecen, por ejemplo, al recrear una pista de bádminton colgando la red de dos árboles y marcando los límites del terreno de juego con pintura blanca sobre el pavimento en un rincón de los jardines de las Voltes d'en Cirès en el barrio del Raval; al servirse de una fachada lateral del pabellón deportivo de la Vall d'Hebron como muro para jugar frontenis; o al organizar de forma periódica partidos de criquet en la plaza de Manuel Vázquez Montalbán por parte de adolescentes de aspecto indostaní, precisamente bajo el cartel que el ayuntamiento ha colocado allí para informar de la prohibición de llevar a cabo cualquier tipo de juego con pelota.

Los espacios de representación se exhiben de tan diferentes modos a lo largo de los recorridos barceloneses que sería demasiado extenso nombrarlos aquí. Todas estas vivencias coinciden en dar nuevos significados al espacio, impugnando el orden programado por el urbanismo oficial de Barcelona, pero también comparten volatilidad y precariedad porque son constantemente perseguidos y sancionados por la legalidad municipal y su tendencia a un reduccionismo que invisibilice el conflicto.

\section{Conclusiones}

\author{
Esto es lo que espero de una ciudad: \\ que constantemente me sacuda. \\ Por definición, cualquier tipo de \\ planificación urbanística ha de \\ tender a una cierta homogeneidad. \\ La ciudad es lo contrario. La \\ ciudad quiere definirse a través de \\ contradicciones, quiere explotar.
}

Hans Kollhoff y Wim Wenders

Para responder a la pregunta de cómo se da la relación entre el entorno construido urbano y la sociedad que es su usuaria he planteado la aplicación de la teoría de los tres momentos del espacio de Lefebvre, articulándola con la metáfora dramatúrgica de origen goffmaniano y a la información etnográfica producida en torno a la observación realizada en tres recorridos predeterminados en el espacio público de la ciudad de Barcelona.

Con los datos etnográficos obtenidos por la observación participante en los tres itinerarios trazados, las entrevistas con los usuarios y el recurso a diferentes fuentes secundarias, he podido analizar, desde el patrón de la trialéctica espacial, cómo el espacio urbano es producto de un hacer social que puede desvelársenos bajo los aspectos de lo practicado, lo concebido y lo vivido. Aspectos que no se presentan segregados en la experiencia cotidiana, pero que aquí son aislados analíticamente para descubrir la mecánica que opera en la relación entre las personas y su entorno urbanístico. A su vez, para reforzar la idea de que los hechos observados no existen porque posean una naturaleza que determine su destino, sino que se construyen socialmente, vinculo de manera metafórica los momentos del espacio a lo dramatúrgico. Así, asimilo la práctica del espacio a una interpretación ritual -ritual en sentido adjetivo- de la actividad cotidiana de los usuarios en su espacio público habitual por la que los sujetos ejercen como actores que interpretan un papel en el teatro urbano. Según esta premisa metafórica, el espacio concebido es comparable al decorado de una obra teatral que, en cuanto decorado, es un simulacro, una apariencia que busca imponerse a los actores para obligar a ciertas conductas. Por último, el espacio vivido existe cuando los urbanitas actúan improvisando roles que no están determinados ni por lo concebido ni por lo practicado, los sujetos se manifiestan de forma creativa y espontánea poniendo en entredicho el statu quo vigente.

La experiencia de los usuarios en el espacio público observado circula entre esos tres momentos con diferentes intensidades: con una fuerte tendencia a someterse al orden impuesto por el poder de lo concebido y decantándose habitualmente hacia las coherencias de la vida cotidiana de lo percibido o, en otros casos, resolviéndose por las impugnaciones de lo vivido. $\mathrm{El}$ espacio es un proceso en cambio continuo que, a pesar del decorado imaginado por los poderes políticos y económicos vigentes en la actual fase neoliberal con su "frenético capital urbanizador globalizado" (Harvey, 2013: 14), alberga el potencial de creatividad y de transformación capaz de impugnar la idea de un espacio aparentemente neutro y carente de ideología. La improvisación que pertenece al momento del espacio vivido de la urbe se presenta como alternativa innovadora al espacio concebido, aunque, como mínimo, sólo sea para demostrar que la fructífera y diversa complejidad de la vida de la ciudad y su sociedad no pueden ser reducidas a simples parámetros técnicourbanísticos, arquitectónicos o legales.

El encuentro espontáneo, la inestabilidad y el conflicto aparecen de manera inevitable en las calles y plazas de Barcelona como muestras de la vida humana en espacios urbanos, como incógnitas que, afortunadamente, no se pueden resolver porque, en cierta forma, la sociedad que habita el espacio público es infinita. 


\section{Fuentes}

\section{Augoyard, JEAN-FrançOIS}

1979 Pasàpas.Essaisurlecheminementquotidienen milieu urbain, Éditions du Seuil, París, 185 pp.

Bachelard, Gastón

2000 La poética del espacio, Fondo de Cultura Económica, Buenos Aires, 208 pp.

BALANDier, GEORGE

1994 El poder en escenas. De la representación del poder al poder de la representación, Paidós, Barcelona, 187 pp.

CAPEl, Horacio

1983 Capitalismo y morfología urbana en España, Los Libros de la Frontera, Barcelona, 142 pp.

Certeau, Michel de

2000 La invención de lo cotidiano. 1.- Artes de hacer, Universidad Iberoamericana/Instituto Tecnológico de Estudios Superiores de Occidente, México y Guadalajara, 229 pp.

Cruces, Francisco

2007 Símbolos en la ciudad. Lecturas de antropología urbana, Universidad Nacional de Educación a Distancia, Madrid, 170 pp.

Debord, GuY

2009 La sociedad del espectáculo, Pre-Textos, Valencia, $176 \mathrm{pp}$.

Delgado, Manuel

1999 El animal público. Hacia una antropología de los espacios urbanos, Anagrama, Barcelona, $218 \mathrm{pp}$.

Delgado, Manuel

2000 "Etnografía de los espacios urbanos", en Danielle Provansal (coord.), Espacio y territorio, miradas antropológicas, Publicacions Universitat de Barcelona, Barcelona, pp. 45-54.

Delgado, Manuel

2001 Memoria y lugar, el espacio público como crisis de significado, Universidad Politécnica de Valencia, Valencia, 48 pp.

DuCH, Lluís

2000 Llums i ombres de la ciutat. Antropologia de la vida quotidiana III, Publicacions de l'Abadia de Montserrat, Barcelona, 494 pp.

FERnÁndez, ANTONIO

1990 La metrópolis vacía. Aurora y crepúsculo de la arquitectura en la ciudad moderna, Anthropos, Barcelona, 206 pp.

Ganau, JoAn

1997 "La ciutat com a museu. Les obres de reforma interior i el naixement del barri Gòtic de Barcelona, 1907-1930", en Joan Roca (coord.), Expansió urbana i planejament a Barcelona, Institut de Cultura de Barcelona y Proa, Barcelona, pp. 193-206.

García, Raúl

2012 "La ciudad también se vive en los jardines. Una aproximación etnográfica a los interiores de manzana de Barcelona", en Gazeta de Antropología, núm. 28 (1), artículo $18<$ http: / / www.gazeta-antropologia.es $/ ? \mathrm{p}=131>$ [26 de febrero de 2018].

Giglia, Angela

2012 El habitar y la cultura. Perspectivas teóricas $y$ de investigación, Anthropos/Universidad Autónoma Metropolitana-Iztapalapa-División de Ciencias Sociales y Humanidades, Barcelona y México, 159 pp.

Goffman, ERving

1970 Ritual de interacción, Tiempo Contemporáneo, Buenos Aires, 237 pp.

Goffman, ERVING

1979 Relaciones en público. Microestudios del orden público, Alianza, Madrid, 379 pp.

Goffman, ERVING

1981 La presentación de la persona en la vida cotidiana, Amorrortu, Buenos Aires, 273 pp.

Goffman, ERving

1991 Los momentos y sus hombres. Textos seleccionados y presentados por Yves Winkin, Paidós, Barcelona, $231 \mathrm{pp}$.

HANNERZ, UlF

1986 Exploración de la ciudad. Hacia una antropología urbana, Fondo de Cultura Económica, México, 386 pp.

HaRvey, David

1998 La condición de la posmodernidad. Investigación sobre los orígenes del cambio cultural, Amorrortu, Buenos Aires, 401 pp.

Harvey, David

2013 Ciudades rebeldes. Del derecho a la ciudad a la revolución urbana, Akal, Madrid, 238 pp.

Heidegger, Martin

1997 Filosofía, ciencia y técnica, Universitaria,

Horta, Gerard Santiago de Chile, 304 pp.

2010 Rambla del Raval de Barcelona: de apropiaciones viandantes y procesos sociales, El Viejo Topo, Mataró, $291 \mathrm{pp}$.

Joseph, IsAaC

1988 El transeúnte y el espacio urbano. Ensayo sobre la dispersión y el espacio público, Gedisa, Barcelona, 159 pp.

Joseph, IsAac

1999 Retomar la ciudad. El espacio público como lugar de la acción, Universidad Nacional de Colombia, Medellín, 81 pp.

Kollhoff, Hans

Y WIM WENDERS

1988 "La ciutat. Conversa entre Wim Wenders i Hans Kollhoff", en Quaderns d'ArquitecturaiUrbanisme, núm. 177, pp. 44-79.

LefEBVRe, HenRI

1972 La revolución urbana, Alianza, Madrid, 198 pp.

LEFEBVRE, HENRI

2013 La producción del espacio, Capitán Swing Libros, Madrid, $451 \mathrm{pp}$.

Low, Setha

1996 "The Anthropology of Cities: Imagining and Theorizing the City", en Annual Review Anthropology, núm. 25, pp. 383-409.

MALINOWSKI, BRONISLAW

1986 Los argonautas del Pacífico occidental, Planeta DeAgostini, Barcelona, 2 ts., 505 pp.

Merleau-Ponty, Maurice

2003 El mundo de la percepción. Siete conferencias, Fondo de Cultura Económica, Buenos Aires, 84 pp.

Muñoz-Alonso, LoREnA

2012 "Líneas de fuga: Resistencia urbana, sueños y juegos", en José Guirao (coord.), Líneas de deseo/Desire Lines, Caja Madrid, Barcelona, pp. 8-15. 
Pinçon, Michel

y Monigue Pinçon-Charlot

2013 Paris. Quinze promenades sociologiques, Payot \& Rivages, París, 326 pp.

Radcliffe-Brown, Alfred R.

1986 Estructura y función en la sociedad primitiva, Planeta DeAgostini, Barcelona, 249 pp.

SAnsot, Pierre

2004 Poétique de la ville, Payot \& Rivages, París, $626 \mathrm{pp}$.

Segalen, Martine

2005 Ritos y rituales contemporáneos, Alianza, Madrid, 186 pp.

Signorelli, Amalia

1999 Antropología urbana, Anthropos/Universidad
Autónoma Metropolitana-Iztapalapa-División de Ciencias Sociales y Humanidades, Barcelona y México, $252 \mathrm{pp}$.

Simmel, Georo

1988 Sociologia. Investigacions sobre les formes de la socialització, vol. II, Edicions 62, Barcelona, 407 pp.

SOJA, EDWARD

1996 Thirdspace: Journey to Los Angeles and Other Real-and-Imagined Places, Blackwell, Malden, $334 \mathrm{pp}$.

Velasco, Honorio M.

1996 "La difuminación del ritual en las sociedades modernas", en Revista de Occidente, núm. 184, pp. 103-123. 